\title{
ESCOLA CASA VERDE: RUPTURAS E REORGANIZAÇÃO DO PROCESSO ENSINO APRENDIZAGEM
}

\author{
Lindalva Pessoni Santos ${ }^{1}$ \\ Oscar Ferreira Mendes Neto ${ }^{2}$
}

\begin{abstract}
Resumo: Pensar a educação na atualidade pressupóe estar disposto a refletir sobre as demandas emergentes da sociedade, no intuito de promover uma educação que seja contextualizada e estabeleça relaçóes com a vida das pessoas de forma significativa. As teorias da transdisciplinaridade e da complexidade surgem como possíveis propostas de mudanças nas práticas educacionais que se fundamentam na religação dos saberes científicos aos saberes culturais e rompem com as dualidades existentes, apresentando uma visão global em relação ao aprendizado e à vida. A autohetero-ecoformação, exercício formativo que parte das relaçôes do indivíduo com ele mesmo, com a sociedade e com o meio-ambiente, também se torna fundamental para discutir as novas demandas da educação, no que se refere à formação para o exercício de cidadania crítica perante a sociedade e a preservação do meio ambiente, criando uma cultura de cidadão planetário com compromisso para com as geraçóes futuras. Desse modo, o presente trabalho faz uma breve apresentação sobre os pressupostos teóricos acerca da transdisciplinaridade, complexidade e sobre a criatividade das escolas ao desenvolverem suas práticas pedagógicas pautadas nessas teorias. A criatividade percebida
\end{abstract}

1 Mestre em Educação pela Faculdade de Educação/Universidade Federal de Goiás (2011). Especialista em Planejamento Educacional pela UNIVERSO (1993). Especialista em Matemática e Linguagem para as séries iniciais do Ensino Fundamental pela UFG (1997). Especialista em Formação sócio- econômica do Brasil pela UNIVERSO (2002). Professora de Estágio Curricular Supervisionado na Educação Infantil pela Universidade Estadual de Goiás - UEG Câmpus Inhumas. Professora da Rede Pública Estadual de Educação de Goiás. Professora do Programa de Pós-Graduação Lato Sensu em Transdisciplinaridade e Interdisciplinaridade na Educação, pela Universidade Estadual de Goiás - UEG Câmpus Pirenópolis. Membro do Grupo de Pesquisa em Rede Internacional Investigando Escolas Criativas e Inovadoras (CNPq - Diretório dos Grupos de Pesquisas no Brasil. Coordenadora do Projeto de Pesquisa: Escolas criativas e inovadoras. E-mail: lindalpessoni@yahoo.com.br. CV: http://lattes.cnpq.br/8331676592474890.

2 Pedagogo pela Universidade Estadual de Goiás, Câmpus Inhumas (UEG - 2014). Especialista em Gestão Escolar pela Faculdade Brasileira de Educação e Cultura (FABEC - 2015). Especialista em Transdisciplinaridade e Interdisciplinaridade na Educação, pela Universidade Estadual de Goiás, Câmpus Inhumas (UEG-2017). Aluno do Programa de Pós-Graduação Stricto Sensu Interdisciplinar em Educação, Linguagem e Tecnologias, pela Universidade Estadual de Goiás, Câmpus Anápolis de Ciências Socioeconômicas e Humanas. Membro do Grupo de Pesquisa em Rede Internacional Investigando Escolas Criativas e Inovadoras (CNPq - Diretório dos Grupos de Pesquisas no Brasil Lattes). E-mail: oscar.hand@hotmail.com. CV: http://lattes. cnpq.br/3125331759859434 
nas práticas docentes deve ser observada sob a perspectiva da necessidade de apresentar um processo educativo que seja significativo, reflexivo e contextualizado, por meio de novas atitudes que rompam com o formato tradicional de ensino centrado na figura do professor e em conteúdos estéreos. A par disso, neste estudo, apresenta-se a Escola Casa Verde ${ }^{3}$ que demonstra características que superam práticas instituídas e naturalizadas nas escolas formatadas pelo paradigma tradicional. Nela, percebe-se, ainda, indícios de criatividade e inovação em seu projeto pedagógico, uma concepção transformadora de educação e de sociedade ao atuar numa perspectiva de uma formação mais humana, integral, sensível, consciente imbuída de valores e princípios norteadores de conviver mais harmônico entre os homens e destes com a natureza.

Palavras-chave: Transdisciplinaridade. Complexidade. Criatividade.

\title{
CASA VERDE SCHOOL: RUPTURES AND REORGANIZATION OF THE PROCESS TEACHING LEARNING
}

\begin{abstract}
Thinking about education in nowadays presupposes being willing to reflect on the emerging demands of society, in order to promote an education that is contextualized and establish relationships with people's lives in a significant way. The theories of transdisciplinarity and of the complexity arise as possible proposals for changes in educational practices that are based on the reconnection of scientific knowledge to cultural knowledge and break with the existing dualities, presenting a global vision in relation to learning and life. The Self-hetero-ecoformation, a formative exercise that starts from the individual's relations with himself, with society and with the environment, also becomes fundamental to discuss the new demands of education, as regards training for the exercise of critical citizenship before society and the preservation of the environment, creating a culture of planetary citizen with commitment to future generations. Thus, the present paper makes a brief presentation on the theoretical assumptions about transdisciplinarity, complexity and about the creativity of schools when developing their pedagogical practices based on these theories. The perceived creativity in teaching practices must be observed from the perspective of the need to present an educational process that is meaningful, reflective and contextualized, through new attitudes that break with the traditional teaching format centered on the teacher figure and stereo contents. In addition, in this study, we present the Casa Verde School that demonstrates characteristics that overcome practices instituted and naturalized in schools shaped by the traditional paradigm. In it, we can also see signs of creativity and innovation in its pedagogical project, a transformative conception of education and society, while acting in the perspective of a more humane, integral, sensitive, conscious formation imbued with values and guiding principles of more harmonical living between men and them with the nature.
\end{abstract}

Keywords: Transdisciplinarity. Complexity. Creativity.

3 A seleção da escola se deu a partir de diferentes aproximações: primeiramente através da leitura de um capítulo, na Revista da UFG, Polyphonía, Dossiê: Escolas Criativas v.27, n.1, jan/jun, 2016 intitulado de Casa Verde: do plantio à colheita - pedagogia do quintal; visita ao site e blog da escola, contato com seu projeto em um Curso de Extensão intitulado de Escolas Criativas e Aportes Teórico-metodológicos da Complexidade e da Fenomenologia na Educação (2016) oferecido pelos professores Marilza Vanessa Suanno (UFG), Carlos Cardoso (UFG) e João Henrique Suanno (UEG). 


\section{Introduçáo}

O desenvolvimento de práticas pedagógicas que se diferenciam dos procedimentos tradicionais está presente em diversas pesquisas atuais como objeto de estudo. Tais pesquisas apresentam novas formas de produção/estímulo do conhecimento relacionados às necessidades e contextos educacionais. A teoria transdisciplinar (NICOLESCU, 1999; SUANNO, 2013), que diz respeito a uma religação entre os diversos saberes; juntamente com o exercício da criatividade (MORAES; RIBEIRO, 2014; SUANNO, 2009, 2014, 2016), bem como do pensamento complexo (MORAES, 2014; SANTOS, 2009;), fomentam uma nova concepção de educação, de ensino, de aprendizagem, de vida. Esta concepção instiga as pessoas a estabelecerem relações entre os saberes científicos, os saberes culturais, os saberes espirituais, o meio ambiente e a vida proporcionando a reflexão e contextualização do conhecimento de forma crítica e responsável para com a sociedade e com as gerações futuras.

Neste trabalho, pautado na abordagem transdisciplinar, apresentamos a Escola Casa Verde 4 , uma instituição da rede particular, situada na cidade de Aparecida de Goiânia, Goiás, que atende vinte e sete crianças, da educação infantil às séries iniciais do ensino fundamental. A pesquisa foi de natureza qualitativa e os procedimentos utilizados foram: a Pesquisa Documental - tendo como fonte o Projeto Político Pedagógico (PPP, 2016) da Escola- e a Pesquisa de Campo - entrevistas concedidas pelos seus idealizadores/gestores e de um professor. De posse das análises, corroboradas pelo referencial teórico citado, elencamos elementos característicos da transdisciplinaridade, da complexidade e da criatividade presentes na proposta da Escola Casa Verde.

O trabalho foi estruturado da seguinte forma: em um primeiro momento, enfatizamos algumas concepções sobre a teoria transdisciplinar e o pensamento complexo, assim como alguns elementos indicativos sobre o que venha ser uma prática pedagógica criativa. Posteriormente, apresentamos a instituição educacional em estudo e algumas de suas concepções e práticas em consonância com o referencial teórico que subsidia este trabalho. Por fim, algumas considerações provisórias sobre a temática da discussão, considerando que tal estudo está em andamento.

4 A Escola Casa Verde passou a ser campo, a partir de fevereiro de 2017, do Projeto de Pesquisa SANTOS, Lindalva Pessoni. Escolas criativas e inovadoras, UEG, Câmpus Inhumas, com vigência de agosto de 2016 a julho de 2018, após seus gestores Elizete Maria de Lima e João Batista de Lima analisarem criteriosamente o teor do referido Projeto que tem como objetivo geral: investigar, identificar e analisar o potencial inovador e criativo de escolas do Estado de Goiás. 


\section{Transdisciplinaridade, Complexidade e Criatividade na educaçáo: novas reflexóes e proposiçóes}

Durante muito tempo, a visão de mundo e suas práticas foram desenvolvidas por meio do modelo cartesiano, positivista, fragmentado e desconexo. Essa fragmentação provocou um distanciamento entre os saberes, o seu uso na sociedade e a relação entre eles e a vida. Em contraposição a este modo de pensar e agir, e, mediante as demandas atuais, surge uma nova perspectiva de trabalho educativo pautada nas concepções da transdisciplinaridade e da complexidade; uma visão que considera a integração dos saberes e das diferentes dimensões do humano.

A Carta da Transdisciplinaridade, documento internacional elaborado durante o I Congresso Mundial de Transdisciplinaridade (1994) define que:

A Transdisciplinaridade é complementar à abordagem disciplinar; ela faz emergir novos dados a partir da confrontação das disciplinas que os articulam entre si; ela nos oferece uma nova visão da Natureza e da Realidade. A transdisciplinaridade não procura o domínio de várias disciplinas, mas a abertura de todas as disciplinas ao que as une e as ultrapassa (Art. $3^{\circ}$ ); A pedra angular da transdisciplinaridade reside na unificação semântica e operativa das acepções através e além das disciplinas. Ela pressupõe uma racionalidade aberta, mediante um novo olhar sobre a relatividade das noções de "definição" e de "objetividade". O formalismo excessivo, a rigidez das definições e o exagero da objetividade, incluindo-se a exclusão do sujeito, conduzem ao empobrecimento (Art. $4^{\circ}$ ); A visão transdisciplinar é resolutamente aberta na medida em que ela ultrapassa o campo das ciências exatas devido ao seu diálogo e sua reconciliação, não somente com as ciências humanas, mas também com a arte, a literatura, a poesia e a experiência (Art. $5^{\circ}$ ).

O exercício da transdisciplinaridade possibilita que o conhecimento seja ampliado por meio da relação entre as disciplinas, proporcionando ir além dos saberes presentes em cada uma delas, estabelecendo relações entre os saberes já produzidos e o mundo, estimulando a produção de novos saberes. Desse modo, a transdisciplinaridade, conforme o prefixo "trans" indica, diz respeito àquilo que está ao mesmo tempo entre as disciplinas, por meio das diferentes disciplinas e além de qualquer disciplina. Seu objetivo é a compreensão do mundo presente, para o qual um dos imperativos é a unidade do conhecimento (NICOLESCU, 1999).

A teoria transdisciplinar surge como uma proposta que não exclui os saberes disciplinares, mas que estabelece conexões entre eles, associando as partes ao todo, possibilitando ir além do conhecimento fragmentado, de modo que este estabeleça diálogo com o contexto sócio-histórico-cultural emergente, suas demandas e especificidades.

Suanno (2013) afirma que a prática pedagógica transdisciplinar possui um potencial construtivo e formador, já que engloba diversos saberes, transcende as disciplinas e rompe com a linearidade e a fragmentação do conhecimento. A transdisciplinaridade se apresenta como uma prática que possui como ponto central, a articulação entre os saberes, religar os conhecimentos e ressignificar 
esses conhecimentos religados, por meio de um movimento cíclico, dialógico e hologramático.

Nesta perspectiva educativa, o indivíduo é tratado como sujeito ativo do processo de formação, sendo sujeito e objeto do mesmo. Desse modo, ele é considerado um ser múltiplo e complexo, sendo um ser biológico, cognitivo, psicológico, social, afetivo, político, moral, ético, lúdico, cultural, histórico, poético, prosaico, entre outras características.

O pensamento complexo e o paradigma da complexidade dialogam com a teoria transdisciplinar em uma relação de complementaridade. Sendo assim, o pensar complexo apresenta a necessidade de um novo pensamento sobre o meio e conhecimento no qual estamos inseridos, estimulando o questionamento e a reflexão sobre as atitudes humanas em relação à sociedade e o meio, provocando a ampliação da consciência, religando a cultura científica à cultura humanística.

Freire e Leffa (2013), ao abordarem a teoria de tripolar de formação ou lógica ternária de formação de Pineau, apresentam a relação dialógica e hologramática da formação entre o sujeito, a sociedade e a natureza. Nesse sentido, consideram o sujeito como sujeito e objeto de sua formação (autoformação); as intervenções dos indivíduos uns sobre os outros, a (heteroformação); a ação dos indivíduos sobre o meio ambiente e do ambiente sobre os indivíduos, as dimensões ecológicas e ambientais no processo de formação (ecoformação).

A esse respeito, Suanno (2013) afirma que esse movimento, contribui para a formação de um sujeito/sociedade comprometido com o meio social e ambiental em que estão inseridos, ampliando a consciência e fazendo emergir novas relações com o conhecimento, novas relações entre os sujeitos, com a natureza, com as culturas e com a transcendência.

Santos (2009) afirma que a teoria da complexidade está associada à teoria da transdisciplinaridade e vice-versa, de forma dialógica e complementar. Para a autora, tais teorias surgem a partir do avanço do conhecimento e do desafio apresentado pela globalidade para o século XXI. Para a autora:

Os princípios da teoria da complexidade e da transdisciplinaridade ao servirem de instrumentos para a observação da realidade revelam a defasagem conceitual da prática educacional, realçando as concepções ancestrais tácitas na estrutura social, cultural-mental da sociedade moderna e apontam para a superação do modo de pensar dicotômico das dualidades cartesianas (sujeitoobjeto, parte-todo, razão-emoção, etc.) (Descartes, 1973), indicando um modo de pensar articulado e contextualizado (SANTOS, 2009, p.17).

As considerações da autora mostram que ambas as teorias buscam o religar entre os conhecimentos científicos, os conhecimentos populares, os saberes culturais, as múltiplas dimensões do humano e as demandas sociais atuais, rompendo com a fragmentação e as dualidades existentes.

Suanno (2009) afirma que a complexidade possui como um de seus fundamentos a negação da simplificação, se apresentando como teoria capaz de estabelecer diálogo entre as partes e o todo, entre as ambiguidades, rompendo com 
a fragmentação e com o binarismo, pois o pensamento é ampliado, sistêmico e dialógico, sendo "capaz de religar o que a ciência moderna fragmentou, nutrida pela complexidade, apoiado na busca de um novo olhar sobre a realidade" (SUANNO, 2009, p.83).

Ao lançar mão das teorias da complexidade e da transdisciplinaridade é possível conceber novas atitudes no cenário educacional, de modo que possa estabelecer uma formação mais ampla e humanística. Sendo assim, tais teorias contribuem para relacionar os diversos saberes à vida, possibilitando o desenvolvimento de uma comunidade que estabeleça relações com o meio ambiente de forma mais coerente e pertinente. Estas atitudes adotadas nas instituições de ensino, alavancadas pela perspectiva da complexidade e da transdisciplinaridade, constituem-se, para muitos autores, como ações criativas por romperem com práticas instituídas e naturalizadas como as únicas formas de pensar e fazer educação.

Moraes e Ribeiro (2014), ao apresentarem propostas e caminhos para a criatividade, afirmam que é necessário construir uma visão sistêmica, possibilitando pensar a dinâmica da vida e perceber a realidade, buscando ressignificar os conhecimentos já estabelecidos de acordo com o contexto sócio-histórico-cultural atual, por meio de novas linguagens. De acordo com as autoras, para enveredar-se na perspectiva docente criativa necessita deixar a terra firma (zona de conforto) em busca de novas ações que inquiete o profissional docente para a tentativa de apresentar novas possibilidades de descobertas, novas respostas e novas perguntas.

Sobre isso, Zwierewicz (2011, p. 143) afirma:

As Escolas Criativas são aquelas que vão adiante do lugar de que partem, oferecem mais do que têm e ultrapassam o que delas se espera, reconhecem o melhor de cada um e crescem por dentro e por fora, buscando o bem-estar individual, social e planetário.

Ao refletir tal afirmativa, notamos a necessidade de romper com a ideia da fragmentação entre os saberes, unindo as partes ao todo e ir além do conhecimento estabelecido, reconhecendo as múltiplas dimensionalidades do humano e valorizando as características individuais de cada ser, rompendo com um padrão a ser seguido e reconhecendo as habilidades de cada um e sua possível participação no meio em que está inserido. Partindo deste princípio, as escolas criativas devem proporcionar uma formação que busque melhorias no contexto individual, social e planetário, uma auto-hetero-ecoformação.

As escolas criativas devem preparar a partir da vida e para a vida, considerando que o conhecimento não deve ser algo que esteja desconectado com a vida e sim a partir das relações estabelecidas entre o sujeito, a sociedade e o meio em que se está inserido. A esse respeito, Zwierewicz (2011) afirma que se deve levar em consideração as questões reais do cotidiano, possibilitando a busca de soluções de problemas por meio da investigação, da análise, da proposição de soluções.

Suanno (2016) afirma que o exercício da criatividade permite formar cidadãos críticos e participativos na comunidade em que vivem, que buscam 
novas possibilidades para as soluções de problemas, bem como para enfrentar as adversidades de forma resiliente, não se contentando com respostas prontas, mas questionando e transformando realidades, considerando melhorias no plano individual, social e planetário, além da afetividade que permeia a vida e as relações entre os seres humanos. Sendo assim, as pessoas tendem a formar uma consciência de responsabilidade para com as outras e para com o planeta.

Inicialmente, é possível afirmar que escolas criativas passam necessariamente por uma reforma no modo de conceber o conhecimento, o ensino, a aprendizagem, a gestão, as relações com a comunidade e os problemas emergentes da sociedade. $\mathrm{O}$ ambiente, geralmente, é instigador e impulsionado por uma liderança estimuladora e criativa, que pode ser representada por professores, membros do grupo gestor, pais, alunos que desafiam a escola a ressignificar o sentido de ensinar e de aprender no mundo atual.

Segundo Suanno (2013), as concepções e práticas adotadas por uma escola criativa advém da necessidade de um outro currículo, neste caso, polivalente, que permita ampliar o que já se conquistou. Para tanto, necessita de uma outra didática que religue a cultura das humanidades e a cultura científica. A escola criativa advém da implantação de uma outra cultura: cíclica, processual, inovadora, sensível, transdisciplinar, comprometida com os problemas fundamentais vividos na atualidade.

A perspectiva, neste modelo de escola, é a de fugir da linearidade, da memorização e repetição de conteúdo sem sentido e possibilitar novas relações e conexões que permitam a criação de práticas que ampliem a consciência humana. O clima é de cumplicidade e corresponsabilidade em relação às aprendizagens coletivas, uma vez que há uma ressignificação na compreensão das conexões entre os aspectos ontológicos, epistemológicos e metodológicos e as implicações no fazer pedagógico. Nesse sentido, mudam-se as concepções de sujeito, objeto e a relação entre eles.

As escolas criativas contribuem para a formação de pessoas semeadoras e polinizadoras de uma educação que compartilha conhecimento sem desconsiderar as emoções, os sentimentos, a responsabilidade consigo, com o outro e com o planeta como um todo; uma educação integrada, fruto da conjunção de valores humanos, sociais e ambientais.

A visão integrada do conhecimento, das atitudes de ensinar e aprender, das ações e reações frente ao que a pessoa é, ao que a pessoa faz, e como ela conhece, possibilita condições mais adequadas de investigar e refletir temas emergentes, e, por meio de um pensamento complexo, religa conhecimentos e desenvolve ações e práticas transformadoras. Estas são movidas por um espírito empreendedor, que faz e refaz, que busca e não teme por errar, que lança mão de ferramentas indispensáveis que transcendem o aqui e agora. São assumidas novas posturas, atitudes, sentimentos, ações e reações frente às questões culturais, sociais, econômicas e políticas, locais e globais, para elaboração de saídas coerentes frente às demandas atuais. 
Uma escola que se intitula criativa, em sentido amplo, deve proporcionar experiências que contribuam para o crescimento individual e social do aluno. Ela deve buscar a formação de um aluno que tenha consciência de seu papel enquanto ator social, que de posse do conhecimento, tem possibilidade de compreender e interferir nos rumos da história. A proposta de trabalho deve ampliar a compreensão e o pensar complexo dos alunos, com o intuito de religar o que está separado numa perspectiva interdisciplinar/transdisciplinar que visa à transformação da escola e da sociedade.

Com a intenção de divulgar práticas pedagógicas criativas, foi criada a Rede Internacional de Escolas Criativas (RIEC), em junho de 2012 em Barcelona, durante a realização do IV Fórum Internacional sobre Innovación y Creatividad: Adversidad y escuelas creativas, tendo como propositor de sua criação Saturnino de La Torre. De acordo com a Ata de Constituição da RIEC, a proposta de criação da Rede teve seus antecedentes a partir pesquisas e investigações na Red de Ecología de Saberes, Red de Formación Universitaria Transdisciplinar (REDFUT) e Rede de escolas criativas iniciada em Barcelona em 2007 e com experiências pioneiras em Orleans (Brasil).

Sediada atualmente em Barcelona, a RIEC permite a cada país instituir diferentes grupos de pesquisas e redes, desde que estes estabeleçam conexões. A rede é composta por membros que, em suas ações buscam instituições criativas e transformadoras, além de contribuírem impulsionando e difundindo essas experiências. Os três principais objetivos (metas) da RIEC são: criar uma consciência coletiva de mudança; gerar ações transformadoras; promover ações investigadoras e polinizadoras.

Ao refletir sobre esses objetivos, é possível conceber sobre a necessidade de mudança na educação, buscando desenvolver práticas pedagógicas a partir de uma perspectiva mais ampla, que considere o humano e suas potencialidades diversas, coletivas e individuais, de forma que se promova conhecimento da vida e para a vida.

As ações, ao serem polinizadas, possibilitam socializar sobre as dificuldades vivenciadas em determinadas instituições e como ações criativas são capazes de contribuir para a superação de tais dificuldades, além de proporcionar uma possível reflexão sobre práticas pedagógicas, aproximando-as do seu cotidiano escolar. No entanto, as práticas criativas não devem se apresentar como "receitas" a serem desenvolvidas, mas como ações que obtiveram êxito em determinado contexto sócio-histórico-cultural.

De acordo com Suanno (2016), uma escola criativa consegue alcançar resultados além da formação de habilidades cognitivas, mas transcendem o conhecimento, aplicando-o à vida. As escolas criativas passam a formar cidadãos críticos e participativos na comunidade na qual estão inseridos, por meio de valores humanos, sociais e de convivência, sendo capazes de se inquietarem com as mazelas e enfrentá-las, transformando o meio em vive e do qual faz parte. 
De acordo com Suanno ( 2014) a ecoformação é definida como a relação entre sujeito, sociedade e natureza; ao ser colocada em prática nas escolas, possibilita uma reflexão sobre a necessidade de repensar a interação entre sujeito e a sociedade em relação à natureza, no intuito de promover uma relação de convivência, considerando o bem estar pessoal e social com o meio ambiente, nunca se esquecendo de preservar para as gerações futuras, fomentando uma formação transdisciplinar em busca de ações sustentáveis entre a natureza e as necessidades humanas.

Suanno (2016) esclarece que as escolas criativas são capazes de reencantar o processo de ensinagem por meio das mudanças nas concepções do ensinar e do aprender. Para isso, conforme o autor:

[...] precisamos de uma escola que não perpetue o modelo tradicional de ensino que está estampado ainda hoje, que motive os professores a ministrar as aulas com mais autonomia criativa, que inspire seus alunos a serem pessoas melhores, a se superarem e que os motive a estudarem com desejo de aprender conteúdo sobre a vida, que trabalhem as disciplinas e perceba a relação do humano com todas as áreas da esfera educacional, social, ecológica e planetária, que atenda às necessidades de formação de um cidadão transformador de sua realidade, que nos dê um sabor de querer não interromper o processo de aprendizagem iniciado por alunos e professores e dê vontade de retornar à ela para ver amigos, professores e aprender mais, que religue saberes ao invés de dicotomizá-los, que promova a circularidade de conhecimento fugindo da linearidade não relacional, que amplie os olhares para os motivos multidimensionais e utilize da multirreferencialidade para analisar e avaliar fatos e experiências, que ensine a seus alunos a ecologizarem suas ações, seus pensamentos e os ambientes em que se relaciona com outros humanos, que trabalhe com os princípios transdisciplinares, que reintroduza o sujeito cognoscente em seu processo de construção do conhecimento, que tenha professores que ensinem a criatividade aos alunos como algo acessível à todos, cada um ao seu modo, que entenda que a diferença entre as pessoas é um componente que embeleza as relações com surpresas e alegrias, que ajude seus alunos a enfrentar com coragem as adversidades que se apresentam na vida de toda pessoa, que religue a vida com o sentir-pensar-agir (SUANNO, 2016, p.82).

Uma escola que atua sob a perspectiva da criatividade, rompe toda e qualquer fragmentação do conhecimento e do ser humano. Nela, ensina a interpretar e respeitar o mundo em que estamos inseridos e a respeitar e admirar a diversidade existente. Os sujeitos são considerados em suas individualidades, mas no que os une, a humanidade. Os professores devem ter autonomia criativa, capaz de encantar os alunos na busca de conhecimentos auto-hétero-ecoformador. A aprendizagem considera as múltiplas referências e dimensionalidades, além da autorreferencionalidade. Os alunos sentem prazer em frequentar as escolas, em aprender mais e a se relacionarem entre si e com o mundo em que estão inseridos. Os conhecimentos desenvolvidos dialogam e relacionam entre si, rompendo com a linearidade e a fragmentação. 


\section{Escola Casa Verde: a escola-quintal}

A Escola Casa Verde - aprendendo com os pássaros, se apresenta como um grande quintal com plantas diversas do cerrado, flores, folhagens, galinheiro, mesas e bancos debaixo das árvores, casa na árvore, horta, grama, espaço de terra. Objetos que foram descartados assumem novas funções, como botinas, manequins, latas de tinta, carcaças de computadores e moedores de café que se tornam vasos de flores, ou tampas de caixa d'água que, ornamentadas pelas crianças, se tornam lustres. Ainda existem os protagonistas, as crianças que interagem umas com as outras, com os professores e demais funcionários da instituição, de modo respeitoso e afetuoso.

A instituição possui uma concepção de educação integral, propondo "educar as crianças para o exercício pleno da cidadania, com espírito investigador e crítico, capaz de resolver situações que se lhes apresentarem na vida diária" (PROJETO POLÍTICO PEDAGÓGICO, 2016, p.5). Desse modo, os alunos são conduzidos vivenciar experiências que extrapolam os conteúdos científicos, se constituindo como sujeitos da construção sistemáticas do próprio conhecimento.

A escola tem pouco mais de meia dezena de anos, porém, tem uma longa história que antecede sua fundação de acordo com as entrevistas e documentos utilizados nesta pesquisa. Durante uma entrevista semiestruturada, dois dos fundadores/idealizadores desta escola, a professora Elizete Maria de $\mathrm{Lima}^{5}$ e o professor João Batista de Lima ${ }^{6}$, esclareceram que este projeto foi gestado em outros tempos e espaços, nos quais experimentaram e articularam diferentes saberes, fazeres, valores e princípios que, paulatinamente, contribuíram para a formação de uma nova concepção de espaço escolar, de ensino, de aprendizagem, de formação humana.

Ao questionar seus fundadores sobre o projeto da escola, eles afirmam que um diferencial são as experiências, as vivências, os questionamentos e as reflexões que são proporcionadas continuamente às crianças. Conforme os relatos, parte-se, primeiro, da experimentação e das indagações em torno dos conhecimentos que se deseja construir e, paulatinamente, os conceitos são elaborados como forma de agregar também valores como autonomia, respeito ao bem comum, ao meio ambiente, responsabilidade e sensibilidade em relação às questões da vida como um todo.

Uma formação que estimula as crianças a desenvolverem a investigação, a reflexão e a criação de possíveis soluções para problemas presentes no meio em que estão inseridas, possibilita ainda a pensarem a realidade local e atuar na sociedade, por meio de uma cidadania crítica e consciente. Em conformidade com essa afirmação, Libâneo (2011, p. 26) aponta que "a escola deve continuar investindo na

5 A professora será referenciada no trabalho como LIMA1

6 O professor será referenciado como LIMA2 
ajuda aos alunos a se tornarem críticos, a se engajarem na luta pela justiça social, a situarem-se competente e criticamente no sistema produtivo".

A concepção de constituição do espaço da escola no formato de um quintal surge como uma perspectiva que proporciona esta criticidade sobre o meio social/ ambiental e o sistema produtivo. Este espaço possibilita vivenciar o conhecimento a partir das experiências e interações significativas e efetivas, indo além das teorias, experimentando e ressignificando ações reais, concretas, diretamente conectadas com a vida. Lima2 (2017), expõe a necessidade de voltar o olhar para o conhecimento que está presente no quintal da escola, que está presente na natureza.

[...] para aprender a germinação do feijão, eles colocavam um copo com algodão e água, colocava o feijão lá e punha na janela e punha o nome pra acompanhar o processo. Então, pra que fazer aquilo se a natureza tá explodindo aqui fora? Toda hora tá nascendo uma planta, tá nascendo um passarinho, então isso, o que a gente precisa aprender não tá fechado, tá fora, então a natureza ensina. O que a gente precisa aprender, não precisa eu pôr um feijão dentro de um algodão, pois aqui eu tenho um espeço que eu posso plantar uma infinidade de outras coisas que não seja o feijão, né?! Então a criança começa a ..., por exemplo, aqui a gente pega uma lagarta tá aqui e ela vai fazer o casulo, então todo dia a criança tá aqui e tá vendo o processo, quantos dias ela ficou encasulada, isso correspondeu a quantas semanas, isso passou quantas luas, então, o tanto de coisas que a gente pode explorar com o que tá acontecendo já, não precisa trazer nada de fora, tá tudo aqui. Então acho a gente tem..., acho que a proposta seria essa, está buscando o conhecimento dentro que eles estão vivendo. O lema da escola é aprendendo com os pássaros, né?! Então eu acredito que a nossa proposta, da nossa escola, que se diferencia é esse cuidado de demorar o olhar em cima das coisas, aprender com o que a natureza nos expõe, aprender com o que..., por exemplo, a gente vai arrancar um pé de mandioca ou plantar um pé de mandioca, isso tudo a gente aproveita como uma vivência, e essas vivências a criança aprende e nunca mais esquece. Uma vez a gente foi plantar uma cana aqui, a gente falou que a cana veio da Ilha da Madeira, que na época que veio descobrir o Brasil, antes passa na Ilha da Madeira e de lá a cana é originária. Então, a gente vai olhar no mapa o percurso que o navio fez até chegar nessa Ilha da Madeira e daí até o Brasil a gente "tá" explorando a geografia e a história ao mesmo tempo. Então, eu acho que tudo que a gente vai aprender, a gente puder experenciar é o diferencial, aprender e experenciar o que aprende [...].

A partir da análise do Projeto Político Pedagógico (2016) da escola, da dinâmica do seu espaço físico, bem como as declarações dos seus gestores/ idealizadores, obtidas por meio das entrevistas, nos mostram que a escola defende uma proposta na qual leva em consideração as questões relacionadas à natureza, à sociedade e os valores humanos. Apresenta como princípio uma educação sensível, solidária e colaborativa por meio de reflexões diárias sobre a realidade local, ao mesmo tempo fazendo conexões com as questões globais. O intuito é conscientizar não só os alunos, mas a comunidade escolar de que pequenos gestos, como a coleta seletiva, o sistema de compostagem, a reutilização de objetos, o consumo consciente, o cuidado de si, o cuidado com o outro e com a natureza, podem resultar em ações 
positivas que contribuirão para a solução de muitos problemas que assombram a humanidade em relação ao esgotamento dos recursos naturais e os conflitos sociais, étnicos e religiosos.

As questões abordadas no Projeto Político Pedagógico (2016) e reafirmadas nas falas dos gestores/ idealizadores da escola vão ao encontro do pensamento de Suanno (2014, p. 180) que define que "uma escola que trabalha com um projeto criativo ecoformador favorece a responsabilidade, a autonomia, o sentido crítico, a capacidade de tomar decisões, a busca de soluções para os problemas, bem como a criatividade".

Nesse sentido, a escola trabalha os saberes científicos e disciplinares fundamentada nas interações com o outro e com o mundo, possibilitando experimentações e aproximações entre a natureza, a sociedade e o humano, por meio de uma educação sensível, natural e colaborativa. Assim, todos os espaços da instituição se tornam ambientes de aprendizagem em determinados momentos, de acordo com a necessidade ou interesse das crianças, no intuito de permitir esse contato com o meio em que estão inseridos, de modo coletivo. As crianças passam a experimentar, na escola, possíveis aprendizagens com o mundo e com a natureza, de modo que estas aprendizagens se dão em todos os espaços da escola.

O quintal também é ambiente de interações, de brincadeiras, em que as crianças desenvolvem suas fantasias, exploram sua criatividade e imaginação. As crianças podem ser crianças e estabelecem relação com outras crianças nesse espaço, desenvolvendo e ampliando a afetividade, a colaboração, a cooperação e a coletividade necessárias para a vida em sociedade. O espaço físico da escola pode ser definido a partir das considerações de Adriano, Silva e Tomio (2016, p. 389) quando as autoras esclarecem que "[...] espaços constituídos em harmonia com a arquitetura e a natureza, espaços inspiradores para aprender conceitos dos diferentes componentes curriculares, praticar habilidades e vivenciar atitudes na direção de uma compreensão de si, do e com o outro, no mundo".

Outra característica da instituição é ensinar para a vida, propondo "encontrar os próprios caminhos" para a solução de problemas. Desse modo, a escola prima pelo exercício da investigação, do levantamento de hipóteses, da busca individual e coletiva para a soluções de problemas, proporcionando uma formação críticareflexiva sobre o meio em que se está inserido e o convívio em sociedade de forma ética. De acordo com o Projeto Político Pedagógico da instituição:

[...] no desejo de uma educação humanizadora, sócio-ambientalmente sustentável, responsável e crítica, respeitando o tempo necessário à construção de valores, competências e habilidades próprias [...] das crianças, comprometendo-as com a sustentabilidade do planeta [...] (PROJETO POLÍTICO PEDAGÓGICO, 2016, p. 3).

$\mathrm{Na}$ escola, a aprendizagem não se dá unicamente na sala de aula e com o quadro-negro, mas em todos os espaços da instituição. Desse modo,

A depender das atividades propostas, e da curiosidade e do afeto que as move, as crianças se misturam e se visitam; e circulam por diferentes espaços numa 
dinâmica de cooperação que favorece o desenvolvimento da inteligência e da emoção e a alegria e a descoberta dos próprios talentos (CASA VERDE, 2012, p. inicial).

A afetividade é característica presente em ações ecoformadoras, considerando que há a necessidade do trabalho em equipe, as interações sociais, o exercício da alteridade e o cuidado com o outro, com a natureza, além da construção coletiva de conhecimento e a mediação pelos pares. Suanno (2014, p. 175) afirma que "a ecoformação, nutrida pela transdisciplinaridade, se fundamenta na afetividade que permeia a vida, na construção coletiva de saberes e no compartilhar de experiências e sentimentos".

Para vivificar valores como a amizade, a solidariedade, a partilha, valorizar as coisas simples e desenvolver a sensibilidade de celebrar a vida em sua totalidade, a escola estrutura seu trabalho por meio da arte como forma de promover a apropriação dos conhecimentos, valores e a expressão das emoções, da imaginação e dos sentimentos. O Projeto Político Pedagógico (2016, p. 15) da escola traz como um dos objetivos: "proporcionar o reconhecimento da educação pela arte como necessidade oriunda do sujeito [...]”. Conforme Lima 1 (2017):

[...] quando a gente trabalha com os projetos tendo a arte como o veio, a gente tenta fazer, conjugar as competências acadêmicas, com o que Rubem Alves diria mais ou menos assim "o que é para sobreviver, o que é para viver, o que é para a alegria, o que é para a necessidade". Então, a medida que a gente foca os projetos, cada ano a gente contempla um subprojeto dentro desse projeto maior, é pensando mais ou menos assim, do que adianta as condições de viver se eu não tenho razões para viver, e a razão de viver está na arte, está na beleza, está no prazer de estar, está no prazer de fazer, de aprender [...] (LIMA 1, 2017).

Outra questão que se destaca é a atenção e cuidado ao corpo - em sua totalidade - como questão também essencial, assim como a arte, para a educação e a formação de pessoas mais conscientes, solidárias, criativas e sensíveis. Nas palavras de Cruz ${ }^{7}$ :

[...] O corpo é a própria práxis. Para tanto, é crucial entender o corpo como e além das estruturas biológicas, palpáveis e das suas capacidades motoras e mentais. O ser humano é o seu corpo, em sua complexa totalidade, mesmo que estejamos distantes dessa totalidade. Corpo formado por pensamentos, conhecimentos, memórias, sentimentos, intuições, emoções, imaginários, ideias, desejos, necessidades, vontades, limitações, receios, insuficiências, medos, potencialidades, talentos. Organizado genética, social e culturalmente (CRUZ, 2017).

A concepção de corpo, além das questões físicas, sinaliza que o trabalho não se restringe ao fazer mecânico de exercitar a musculatura, mas parte do pressuposto

7 Rodrigo da Silva Cruz é professor de educação física na Escola Casa Verde. 
de que o corpo abriga outros elementos essenciais que constituem o ser em uma complexa totalidade.

O desenvolvimento das ações educativas realizadas na Escola Casa Verde é norteado pela perspectiva de projetos de trabalho (HERNÁNDEZ, 1998; LEITE, 1996) considerando necessárias algumas mudanças na compreensão sobre o processo ensino-aprendizagem. Nesse processo, o professor assume uma postura de mediador do conhecimento, rompendo com a ideia de detentor único do conhecimento. $\mathrm{O}$ aluno se torna protagonista do processo, abandonando a concepção de um ser submisso no processo e sem conhecimentos prévios. Sendo assim, é estabelecida uma relação de parceria entre os alunos e professores em busca de soluções de problemas e de produção do conhecimento.

A busca de soluções dos problemas reais e comuns devem ser considerados ao desenvolver ações criativas, de modo a integrar as pessoas envolvidas no processo de formação. A Escola Casa Verde, ao lançar mão dessa prática, contribui para a formação integral do ser humano.

O Projeto Horto Ambiental Escolar, por exemplo, é uma das ações desenvolvidas que resulta no processo de compostagem de materiais orgânicos. Esta ação foi pensada a partir de reflexões sobre o destino de materiais orgânicos descartados juntamente com os resíduos sólidos e como isso contribuiria para o aumento de rejeitos em locais inadequados.

A partir dessa ação, foi possível refletir, junto aos alunos, sobre um destino adequado ao material orgânico descartado por meio da compostagem e da utilidade dessa compostagem como fertilizante no plantio realizado na escola. Nesse sentido, foi possível ir além dessas reflexões, proporcionando repensar sobre como aproveitar de maneira inteligente os recursos que possuímos sem que haja desperdício e agir de maneira ecológica. A ação envolve toda a comunidade escolar, com a coleta sendo realizada às sextas-feiras e havendo um revezamento semanal de cada turma, que é responsável por colocar o material orgânico recolhido na compostagem, durante as aulas de Educação Ambiental.

A busca de ações, tanto para reduzir quanto para destinar adequadamente os resíduos, é preocupação mundial. A compostagem, conforme vem sendo trabalhada na escola, além de abarcar conteúdos curriculares obrigatórios na Educação Básica, traz à tona situações sociais reais, sob as quais se estruturam novas possibilidades e soluções. Coletando e tratando semanalmente parte dos resíduos orgânicos produzidos nas residências dos alunos, contribui para a adoção de valores e atitudes conscientes e responsáveis.

Ao realizar este projeto, a escola consegue relacionar o conhecimento científico com o meio em que estão inseridos seus educandos, apresentar e construir significados para a vida, contribuindo para a realidade local e mostrando para a comunidade que pequenos gestos podem resultar em grandes ações que podem contribuir para a solução de problemas, que, nesse caso, o descarte de materiais orgânicos que servirá como adubo para a produção de plantas alimentícias e 
ornamentais e evitando, assim, o acúmulo de resíduos de forma indevida, seja nas ruas ou nos lixões/aterros sanitários.

Consciente da relevância da pedagogia de projetos e da necessidade de se educar para a vida e para a sociedade, considerando as necessidades atuais do meio em que vivemos, a Escola Casa Verde desenvolve projetos voltados para o desenvolvimento da consciência de preservação e relação com o meio ambiente. É importante ressaltar que, nessa perspectiva, o meio ambiente não se restringe ao ambiente externo a cada pessoa, mas também interno, considerando o corpo humano um meio ambiente e a necessidade de preservação também deste.

Os primeiros dados coletados, as primeiras análises da Escola Casa Verde apontam características que superam práticas instituídas e naturalizadas nas escolas formatadas pelo paradigma tradicional. Desse modo, o projeto, o olhar dos gestores / fundadores e de toda equipe que compõe a escola pesquisada, demonstram uma concepção transformadora de educação e de sociedade ao atuarem numa perspectiva de uma formação mais humana, integral, sensível, consciente, imbuída de valores e princípios norteadores de um conviver mais harmônico entre os homens e estes com a natureza.

\section{Consideraçóes finais}

Este estudo nos permitiu refletir acerca da necessidade de se repensar as práticas educativas, de modo que se possa reconsiderar as relações estabelecidas entre o conhecimento sistematizado e a vida; buscando entender como esta relação pode contribuir para a solução de problemas atuais e emergentes, pode buscar o desenvolvimento de novas práticas que possibilitem melhorias na qualidade de vida das pessoas em escala individual e coletiva, considerando também a necessidade de uma relação ternária entre as pessoas e o meio-ambiente.

A Escola Casa Verde vem apresentando indícios de criatividade em suas práticas pedagógicas, desenvolvidas em consonância com as teorias da transdisciplinaridade e da complexidade. Ao direcionar a educação para a formação que vai além dos conhecimentos já estabelecidos e buscar uma nova abordagem, no intuito de buscar uma formação ativa, que investiga, que propõem soluções, que interage com a sociedade e com o meio-ambiente, a escola está indo além do ponto de partida, formando criticamente para o exercício humano em relação consigo mesmo, com o outro e com a natureza.

À luz de uma nova cultura, vimos nesta escola elementos indicativos de ruptura com a lógica da fragmentação disciplinar do conhecimento, ao promover novas relações com o planeta, atribuindo importância aos valores humanos e sociais, promovendo uma educação da vida para vida, nutridas por valores sócio afetivos, ambientais, de solidariedade e de colaboração.

Refletir sobre novas práticas que estabeleçam relações entre os conhecimentos e a vida torna-se uma necessidade contemporânea latente, não podendo mais serem ignoradas essas associações entre os saberes e a realidade vivenciada na sociedade. 
A escola deve proporcionar meios para que as pessoas tenham possibilidades para propor soluções às situações que lhe são apresentadas cotidianamente de forma a garantir uma vivência mais harmoniosa entre os homens e deste com o meio ambiente.

\section{Referências}

ADRIANO, Graciele Alice Carvalho; SILVA, Vera Lúcia de Souza e; TOMIO, Daniela. Com(viver) em espaços de uma escola sustentável e criativa. Polyphonía, v. 27, n.1 jan/jun. 2016, p. 367-391.

\section{CARTA DA TRANSDISCIPLINARIDADE. I Congresso Mundial de}

Transdisciplinaridade. Portugal, Arrábida, 1994. Disponível em: http://cetrans.com. br/wp-content/uploads/2014/09/CARTA-DA-TRANSDISCIPLINARIDADE1.pdf. Acessado em 01 de maio de 2017.

CASA VERDE, APRENDENDO COM OS PÁSSAROS. Escola Casa Verde.

Disponível em: http://www.escolacasaverde.com.br/. Acessado em 01 de maio de 2017.

CRUZ, Rodrigo da Silva. Rodrigo da Silva Cruz: depoimento [abril, 2017].

Entrevistadora Lindalva Pessoni Santos. Goiânia, Go, 2017. 1 arquivo mp3 (20 min.). Entrevista concedida ao Projeto de Pesquisa: Escolas criativas e inovadoras. UEG, Câmpus Inhumas, 2016/2018.

ESCOLA CASA VERDE: APRENDENDO COM OS PÁSSAROS. Projeto Político Pedagógico (PPP). Aparecida de Goiânia, Goiás, 2016, 56 p.

SUANNO, FREIRE, Maximina; LEFFA, Vilson. A auto-hetero-ecoformação tecnológica. In: Moita Lopes, L.P. (Org.) Linguística Aplicada na Modernidade Recente. São Paulo: Parábola, 2013, p.59-78.

HERNÁNDEZ, Fernando. Os Projetos de trabalho e a necessidade de transformar a escola (II). Revista Presença Pedagógica, v.4, n.21, mai./jun., 1998.

LEITE, Lúcia Helena Alvarez. Pedagogia de Projetos: intervenção no presente. Revista Presença Pedagógica, v.2, n.8, mar./abr., 1996.

LIBÂNEO, José Carlos. Adeus Professor, Adeus Professora? Novas exigências educacionais e profissão docente. 13ª ed. São Paulo: Cortez, 2011.

LIMA, Elizete Maria de. Elizete Maria de Lima. Depoimento [abril, 2017].

Entrevistadores Lindalva Pessoni Santos e Oscar Ferreira Mendes. Aparecida de Goiânia, Go. 1 arquivo mp3 (30 min.). Entrevista concedida ao Projeto de Pesquisa: Escolas criativas e inovadoras. UEG, Câmpus Inhumas, 2016/2018.

LIMA, João Batista de. João Batista de Lima. Depoimento [abril, 2017]. Entrevistadores Lindalva Pessoni Santos e Oscar Ferreira Mendes e Lindalva Pessoni Santos. Aparecida de Goiânia, Go. 1 arquivo mp3 (35 min.) Entrevista concedida ao Projeto de Pesquisa: Escolas criativas e inovadoras. UEG, Câmpus Inhumas, 2016/2018. 
MORAES, Maria Cândida. Didática transdisciplinar como expressão de uma fenomenologia complexa. XVII ENDIPE - Didática e Prática de Ensino: diálogos sobre a Escola, a Formação de Professores e a Sociedade, livro 4. Ceará, EDUCERE, 2014.

MORAES, Maria Cândida; RIBEIRO, Olzeni L. Costa; Criatividade sob a perspectiva da complexidade e da transdisciplinaridade. In: MORAES, Maria Cândida; SUANNO, João Henrique. O pensar complexo na educação: sustentabilidade, transdisciplinaridade e criatividade. Rio de Janeiro: WAK, 2014, p. 147-170.

NICOLESCU, Basarab. Um novo tipo de conhecimento - transdisciplinaridade. $\mathbf{1}^{\mathbf{o}}$ Encontro Catalisador do CETRANS - Escola do Futuro - USP, Itatiba, São Paulo, abril de 1999.

SANTOS, Akiko. Complexidade e Transdiscplinaridade na Educação: cinco princípios para resgatar o elo perdido. In: SANTOS, Akiko; SOMMERMAN, Américo.

Complexidade e Transdisciplinaridade: em busca da totalidade perdida. Porto Alegre: Sulina, 2009, p. 15-38.

SUANNO, João Henrique. Práticas Inovadoras em Educação: uma visão complexa, transdisciplinar e humanística. Anais do IX Congresso Nacional de Educação EDUCERE. Curitiba: PUCPR, 2009, p. 8332-8348. Disponível em: http://www.pucpr. br/eventos/educere/educere2009/anais/pdf/3483_1988.pdf. Acessado em 01 de maio de 2017.

João Henrique. Ecoformação, Transdisciplinaridade e Criatividade: a escola e a formação do cidadão do século XXI. In: MORAES, Maria Cândida; SUANNO, João Henrique. O pensar complexo na educação: sustentabilidade, transdisciplinaridade e criatividade. Rio de Janeiro: WAK, 2014, p. 171-181.

, João Henrique. Por que uma escola criativa? Revista Polyphonía, v.27/1, jan./jun., 2016, p. 81-97. Disponível em: https://www.revistas.ufg.br/sv/article/ view/42289/21287. Acessado em o1 de maio de 2017.

SUANNO, Marilza Vanessa Rosa. Outra finalidade para a Educação: emerge uma didática complexa e transdisciplinar. In: ZWIEREWICZ, Marlene (Org.). Criatividade e inovação no ensino superior: experiências latino-americanas e europeias em foco. Blumenau: Nova Letra, 2013.

ZWIEREZICZ, Marlene. Formação Docente Transdisciplinar na metodologia dos Projetos Criativos Ecoformadores - PCE. In TORRE, Satunirno de la; ZWIEREWICZ, Marlene; FURLANETTTO, Ecleide Cunico. Formação Docente e Pesquisa

Transdisciplinar: criar e inovar com outra consciência. Blumenau: Nova Letra, 2011, p. 141-158. 